\title{
Molecular staging of lung cancer: Real-time polymerase chain reaction estimation of lymph node micrometastatic tumor cell burden in stage I non-small cell lung cancer-Preliminary results of Cancer and Leukemia Group B Trial 9761
}

\author{
Jonathan D'Cunha, MD, $\mathrm{PhD}^{\mathrm{a}}$ \\ Angela L. Corfits, $\mathrm{BA}^{\mathrm{a}}$ \\ James E. Herndon II, $\mathrm{PhD}^{\mathrm{b}}$ \\ Jeffrey A. Kern, MDc \\ Leslie J. Kohman, MDd \\ G. Alexander Patterson, $\mathrm{MD}^{\mathrm{e}}$ \\ Robert A. Kratzke, MDa \\ Michael A. Maddaus, MDa
}

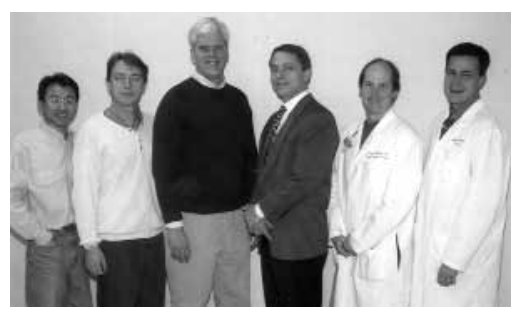

Drs Hoang, Dudek, Kratzke, Maddaus, Dahlberg, D'Cunha (left to right)

\footnotetext{
From the Division of Cardiovascular and Thoracic Surgery, University of Minnesota Medical School, Minneapolis, Minn, ${ }^{a}$ Cancer and Leukemia Group B Statistical Center, Durham, NC, b University Hospitals of Cleveland, Case Western Reserve University, Cleveland, Ohio, ${ }^{c}$ Thoracic Division, State University of New York Upstate Medical University, Syracuse, NY, and Section of General Thoracic Surgery, Division of Cardiothoracic Surgery, Washington University School of Medicine, St Louis, Mo. ${ }^{e}$

Received for publication May 14, 2001; revisions requested July 9, 2001; revisions received July 30,2001; accepted for publication Aug 25, 2001.

Read at the Eighty-first Annual Meeting of The American Association for Thoracic Surgery, San Diego, Calif, May 6-9, 2001.

Address for reprints: Michael Maddaus, MD, Department of Surgery, University of Minnesota, 420 Delaware St SE, Box 207, Minneapolis, MN 55455 (E-mail: madda001@ tc.umn.edu).

J Thorac Cardiovasc Surg 2002;123:484-91 Copyright (C) 2002 by The American Association for Thoracic Surgery.

$0022-5223 / 2002 \$ 35.00+0 \quad \mathbf{1 2 / 6 / 1 1 9 8 8 3}$

doi:10.1067/mtc.2002.119883
}

Objective: The 5-year survival for patients with surgically resected stage I non-small cell lung cancer is only $60 \%$ to $70 \%$, probably because of undetected systemic occult micrometastases. Detection of occult micrometastases in lymph nodes by reverse-transcriptase polymerase chain reaction for carcinoembryonic antigen messenger RNA in non-small cell lung cancer has not been reported. Detection of occult micrometastases by standard reverse-transcriptase polymerase chain reaction provides only yes or no answers about their presence, whereas quantitative real-time reverse-transcriptase polymerase chain reaction permits reproducible quantitation of target molecules. This study evaluated the ability of quantitative reverse-transcriptase polymerase chain reaction to quantitate lymph node occult metastases with carcinoembryonic antigen messenger RNA as a tumor marker.

Methods: Standard reverse-transcriptase polymerase chain reaction and quantitative reverse-transcriptase polymerase chain reaction for carcinoembryonic antigen messenger RNA were performed on 232 lymph nodes from 53 patients with stage I disease (node negative according to histologic examination). Quantitative reverse-transcriptase polymerase chain reaction determined carcinoembryonic antigen messenger RNA quantity by detecting fluorescence increase at a threshold polymerase chain reaction cycle. Threshold polymerase chain reaction cycle values were correlated with standard curves created from serially diluted carcinoembryonic antigen-positive HTB-174 tumor cells to estimate the number of micrometastatic tumor cells in a lymph node.

Results: Detection rates of occult metastases were similar for standard reverse-transcriptase polymerase chain reaction and quantitative reverse-transcriptase polymerase chain reaction at 38 of $232(16.4 \%)$ and 59 of $232(25.4 \%)$, respectively. Upstaging rates among 53 cases of stage I non-small cell lung cancer were also similar for standard reverse-transcriptase polymerase chain reaction and quantitative reverse-transcriptase polymerase chain reaction at 23 of $53(43.4 \%)$ and 30 of $53(56.6 \%)$, respectively. Comparison of positive lymph node stations according to quantitative reverse-transcriptase polymerase chain reaction (threshold polymerase chain reaction cycle $<45$ ) with HTB-174 tumor cell standard curves yielded estimates of metastatic tumor cell burden of $1.07 \times 10^{3}$ to $3.24 \times 10^{5}$ cells per lymph node station (median 7190 tumor cells per lymph node station). 
Conclusions: Standard and quantitative real-time reverse-transcriptase polymerase chain reaction for carcinoembryonic antigen detected occult metastases in patients with stage I non-small cell lung cancer at similar rates; both upstaged about 50\% of cases. Quantitative reverse-transcriptase polymerase chain reaction allows estimation of the number of metastatic cells per lymph node, however, which potentially allows greater precision in predicting recurrence risk.

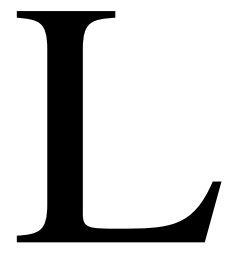

ung cancer is the most common cause of death by malignancy in the United States. ${ }^{1}$ Survival after surgical resection of non-small cell lung cancer (NSCLC) is determined by postoperative pathologic stage, but only $60 \%$ to $70 \%$ of patients with stage I disease (node negative) survive 5 years, ${ }^{2}$ underscoring the high rate of occult micrometastases in "early stage" lung cancer.

Detection of systemic occult micrometastases is possible with immunohistochemical analysis and reverse transcriptase-polymerase chain reaction (RT-PCR). The presence of occult micrometastases in lymph nodes and bone marrow of patients with surgically resected NSCLC, as detected by immunohistochemical analysis (with either cytokeratin antibodies or Ber-EP4 antibodies), correlates with a higher risk of tumor recurrence and death. ${ }^{3,4}$ The prognostic value of occult micrometastatic detection by RT-PCR for tumorspecific messenger RNA (mRNA) in NSCLC is unknown. We previously reported on RT-PCR detection of apomucin type 1 (MUC-1) mRNA in lymph nodes as a means of detecting occult micrometastases ${ }^{5}$; however, subsequent studies revealed the ubiquitous presence of MUC-1 mRNA in many tissues, diminishing its value as a tumor marker. ${ }^{6-8}$

Carcinoembryonic antigen (CEA) is a 200-kd cellsurface glycoprotein involved in cell-to-cell adhesion. RTPCR detection of CEA mRNA has been used as a marker of occult micrometastases in blood, bone marrow, and lymph nodes of patients with gastrointestinal and breast malignancies. ${ }^{9,10}$ Detection of occult micrometastases with RT-PCR for CEA mRNA has been reported in the peripheral blood of patients with NSCLC. ${ }^{11,12}$ However, detection of occult micrometastases in lymph nodes has not been reported.

A potential shortcoming of occult micrometastatic detection by immunohistochemical analysis and standard RTPCR is the binary yes or no result regarding occult micrometastases' presence or absence. Although they are predictive of increased tumor recurrence risk, simple yes or no results fail to further stratify risk. Studies of N2 disease detected by hematoxylin and eosin staining revealed significant survival differences between patients with lymph nodes replaced by tumor and patients with microscopic disease found incidentally after surgical resection. ${ }^{13}$ In a similar vein, tumor recurrence and survivals among patients with lymph nodes negative according to hematoxylin and eosin staining that harbor occult micrometastases may also be related to the number of metastatic tumor cells present.

The technology of automated quantitative real-time RTPCR is now broadly available. ${ }^{14,15}$ Quantitative RT-PCR, unlike other approaches to quantification of polymerase chain reaction (PCR) products, requires no post-PCR product manipulation and can rapidly process many samples (96 reactions in 3 to 4 hours). The purposes of this study were (1) to evaluate the utility of CEA mRNA as a marker for NSCLC occult micrometastases with standard RT-PCR and (2) to develop a quantitative RT-PCR assay for CEA mRNA for quantitation of occult micrometastatic tumor burden.

\section{Methods}

\section{Patients and Specimens}

Institutional review board approval was obtained for all studies. Tissue samples were collected from patients undergoing surgery at institutions participating in Cancer and Leukemia Group B (CALGB) 9761. Eligible patients had radiographically suspected or biopsy-proven NSCLC classified as clinical stage I (T1 N0 or T2 N0) by computed tomographic scan, with the planned treatment of a thoracotomy and resection. Patients with computed tomographic evidence of $\mathrm{N} 2$ disease (lymph nodes $\geq 1.0 \mathrm{~cm}$ ) with negative results of mediastinoscopy were also eligible. All patients enrolled in the study have not had previous chemotherapy or mediastinal radiotherapy. Patients also had no history of previous lung cancer or concomitant malignancy.

At operation, immediately after thoracotomy incision, mediastinal lymph nodes from all accessible lymph nodes were harvested (stations 4, 7, 8, 9, and 10 on the right and 5, 6, 7, and 10 on the left). Then the appropriate pulmonary resection was performed, and intrapulmonary (station 11) lymph nodes were harvested. All lymph node specimens were divided in two: half of each node was sent for routine pathologic testing and the other half was immediately snap-frozen in liquid nitrogen for these studies.

At each institution a surgical pathologist staged the primary tumor in the submitted lung specimen and then provided the participating surgeon with a primary tumor sample that was also snap-frozen. Tissue samples from participating CALGB institutions were shipped on dry ice to our laboratories at the University of Minnesota.

Because eligibility to enter the study was open to patients with suspected or documented NSCLC, tissue specimens were obtained from patients without cancer and from patients with $\mathrm{N} 1$ and N2 disease. These tissue samples were not used in the primary analy- 
sis for this study; however, they were used as an internal source of negative (patients without cancer) and positive (patients with $\mathrm{N} 1$ and N2 disease) control specimens for RT-PCR assays.

\section{Tissue Storage}

Until molecular analysis was performed, frozen tissue specimens from primary tumors, lymph nodes, RNA, and complementary DNA (cDNA) were stored at $-86^{\circ} \mathrm{C}$.

\section{Cell Lines and Cell Culture}

The HTB-174 (human lung adenocarcinoma) and NIH/3T3 (murine fibroblast) cell lines were purchased from American Type Culture Collection (Rockville, Md) and cultured as recommended in medium supplemented with $10 \%$ fetal bovine serum (BioSource International, Inc, Camarillo, Calif).

\section{Cell Line Dilutions for CEA mRNA Standard Curves}

For these experiments the CEA-expressing cell line HTB-174 and the CEA-negative cell line NIH/3T3 were cultured to near $80 \%$ confluence, washed with sterile phosphate-buffered saline solution, trypsinized, centrifuged and washed, and quantitated with a hemocytometer. CEA-expressing cells (10-fold serial dilutions) were mixed with $10^{7} \mathrm{NIH} / 3 \mathrm{~T} 3$ cells (background cells), and total cellular RNA was extracted.

\section{Nucleic Acid Extraction}

Total cellular RNA was extracted from designated tissues with the Trizol method (Life Technologies, Inc, Rockville, Md) as we have previously described elsewhere. ${ }^{5}$ Frozen tissue $(100 \mathrm{mg})$ was washed twice with phosphate-buffered saline solution and lysed in $1 \mathrm{~mL}$ Trizol. Extraction of total RNA yielded $100 \mu \mathrm{g}$ of whole-cell RNA from $1 \mathrm{mg}$ of tissue. All RNA samples were treated with deoxyribonuclease before RT-PCR processing to eliminate any potential genomic DNA. RNA was quantitated by spectrophotometry.

\section{Preparation of cDNA}

Total cellular RNA was reverse transcribed with the Gene-Amp system (PE Corporation, Norwalk, Conn) with random hexamer priming, as previously described. ${ }^{5}$ Briefly, random hexamers $(2.5$ $\mathrm{mmol} / \mathrm{L}$ ) were annealed to $5 \mu \mathrm{g}$ of total RNA for 10 minutes at $25^{\circ} \mathrm{C}$. Reverse transcription (Multiscribe Reverse Transcriptase; PE Corporation) was performed for 30 minutes at $48^{\circ} \mathrm{C}$, followed by enzyme inactivation at $95^{\circ} \mathrm{C}$ for 5 minutes.

\section{Standard CEA RT-PCR}

Standard CEA RT-PCR was performed with a nested PCR approach, as previously described. ${ }^{10}$ In brief, CEA primers that spanned a 160-base pair (bp) fragment of the CEA open reading frame were synthesized and purified commercially (Genosys Biotechnology, Woodland, Tex). Primer sequences used were as follows: A, 5'-TCTGGAACTTCTCCTGGTCTCTCAGCTGG-3'; B， 5'-TGTTAGCTGTTGCAAATGCTTTAAGGAAGAAGC-3'; and C, 5'-GGGCCACTGTCGGCATCATGATTGG-3'. In a 25- $\mu \mathrm{L}$ final volume of 20-mmol/L tris(hydroxymethyl)aminomethane, $\mathrm{pH}$ $8.4,50-\mathrm{mmol} / \mathrm{L}$ potassium chloride, $1.5-\mathrm{mmol} / \mathrm{L}$ magnesium chloride, $200-\mu \mathrm{mol} / \mathrm{L}$ deoxyadenosine triphosphate, $200-\mu \mathrm{mol} / \mathrm{L}$ deoxycytidine triphosphate, $200-\mu \mathrm{mol} / \mathrm{L}$ deoxyguanosine triphos- phate, $200-\mu \mathrm{mol} / \mathrm{L}$ deoxythymidine triphosphate, and 0.05 units Taq DNA polymerase (Life Technologies), $200 \mathrm{ng}$ cDNA was amplified for 20 cycles of PCR at $95^{\circ} \mathrm{C}$ (1 minute) and $72^{\circ} \mathrm{C}(2$ minutes) with primers $\mathrm{A}$ and $\mathrm{B}(200 \mathrm{nmol} / \mathrm{L})$. A final extension step was performed at $72^{\circ} \mathrm{C}$ for 10 minutes. For second-round PCR, 1 $\mu \mathrm{L}$ of the first-round PCR product was subjected to 30 cycles of $\mathrm{PCR}$ at $95^{\circ} \mathrm{C}$ ( 1 minute), $69^{\circ} \mathrm{C}(1$ minutes $)$, and $72^{\circ} \mathrm{C}$ ( 2 minutes $)$. Final extension was again performed at $72^{\circ} \mathrm{C}$ for 10 minutes. For analysis of PCR products, $10 \mu \mathrm{L}$ of PCR product was analyzed by $2 \%$ agarose gel electrophoresis, with ethidium bromide staining used for PCR product analysis. In initial experiments the 131-bp PCR product was eluted and its identity was confirmed by sequence analysis.

\section{CEA quantitative RT-PCR}

For quantitative RT-PCR, a TaqMan probe and primer set for CEA was constructed with the PE Biosystems primer design software (PE Biosystems, Foster City, Calif). The TaqMan probe and primer set for $\beta$-actin was obtained commercially (PE Biosystems). Primer sequences spanned intron-exon junctions to avoid contaminating quantitative RT-PCR product with genomic DNA. To confirm the total gene specificity of sequences derived for primers and probes, we performed BLASTn (National Center for Biotechnology Information, Bethesda, Md) searches against dbEST and the nonredundant set of GenBank, European Molecular Biology Laboratory, and DNA Data Bank of Japan database sequences.

In a 50- $\mu \mathrm{L}$ PCR reaction (final volume after cDNA added), components included 1× TaqMan buffer, 200-mmol/L deoxyadenosine triphosphate, 200-mmol/L deoxycytidine triphosphate, 200-mmol/L deoxyguanosine triphosphate, 200-mmol/L deoxythymidine triphosphate, 200-mmol/L deoxyuracil triphosphate, 5-mmol/L magnesium chloride, 1.25 units AmpliTaq Gold (PE Biosystems), 0.5 units AmpErase uracil N-glycosylase (PE Biosystems), 200-nmol/L 5' primer (5'-GAGGCTCCTGCTCACAGCC-3'), 200-nmol/L 3' primer (5'-TCAATAGTGAGCTTGGCAGTGG-3’), and 100-nmol/L TaqMan probe (5'-CACTTCTAACCTTCTGGAACCCGCCC-3'). Then $200 \mathrm{ng}$ of cDNA was added and subjected to the following cycling conditions in the PE Biosystems Prism 7700: $50^{\circ} \mathrm{C}$ for 2 minutes, $95^{\circ} \mathrm{C}$ for 10 minutes, and 45 cycles at $95^{\circ} \mathrm{C}$ for 30 seconds, at $68^{\circ} \mathrm{C}$ for 30 seconds, and at $72^{\circ} \mathrm{C}$ for 60 seconds. Each assay included a standard curve (described previously) and no-template control. Samples were processed in triplicate. Products were confirmed by $2 \%$ agarose gel electrophoresis with ethidium bromide staining. In initial experiments the expected 69-bp product was also eluted from the agarose gel, with identity confirmed by sequence analysis.

For data analysis, fluorescence emission from the reporter dye (FAM-6-carboxyfluorescein), a covalent modification to the $5^{\prime}$ end of the TaqMan probe, exhibited peak fluorescence emission at $518 \mathrm{~nm}$. A charge-coupled-device camera on the PE Biosystems Prism 7700 instrument collected the laser-excited emission from each sample for real-time analysis of data. With the threshold cycle $\left(\mathrm{C}_{\mathrm{T}}\right)$ defined as the fractional cycle number at which the fluorescence increases with respect to background, the relative amounts of mRNA were calculated. Where appropriate, results are reported as mean $\pm \mathrm{SD}$. For our analysis a lymph node station was 


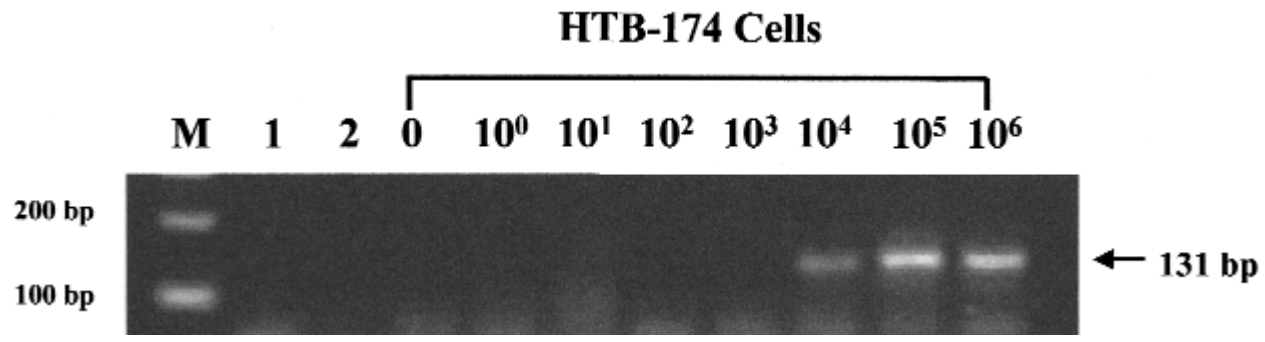

Figure 1. Sensitivity of standard CEA RT-PCR. PCR reactions were analyzed by ethidium bromide-stained $2 \%$ agarose gel electrophoresis. Expected length of amplified PCR product representing CEA mRNA was 131 bp. Lane M, 100-bp molecular weight marker; lane 1, negative control; lane 2, NIH/3T3 cells. Remaining lanes represent serial dilutions of HTB-174 lung adenocarcinoma CEA-positive control cells mixed with 107 NIH/3T3 background cells.

TABLE 1. Clinical and pathologic characteristics of study patients

\begin{tabular}{llc}
\hline & & No. \\
\hline \multirow{2}{*}{ Stage } & IA & 29 \\
& IB & 24 \\
Histologic type & Adenocarcinoma & 32 \\
& Squamous cell carcinoma & 16 \\
& Undifferentiated & 5 \\
\hline
\end{tabular}

considered positive for CEA and $\beta$-actin if it had $>1000$ micrometastatic cells (sensitivity of the assay). For both genes this typically corresponded to a $\mathrm{C}_{\mathrm{T}}$ of less than 42 . Coefficient of variation for triplicate reactions was less than $10 \%$. Coefficient of variation between assays was also less than $10 \%$.

\section{Results}

Patients

Characteristics of patients included in our analysis are summarized in Table 1. Patients had 32 adenocarcinomas, 16 squamous cell carcinomas, and 5 undifferentiated tumors. In all, 53 patients had stage I NSCLC (29 T1 N0 and $24 \mathrm{~T} 2 \mathrm{~N} 0$ ).

\section{Standard CEA RT-PCR}

Studies were first conducted to establish the sensitivity of CEA RT-PCR by analysis of a known number of CEApositive tumor cells in a background of CEA-negative cells. The RT-PCR assay had a sensitivity of $10^{4}$ HTB-174 lung carcinoma cells in $10^{7}$ background NIH/3T3 cells (Figure 1). Identical results were also obtained with K562 cells (a CEA-negative human leukemia cell line) as background cells (data not shown). Then we analyzed lymph nodes for CEA mRNA with the nested RT-PCR assay. Initially 23 control lymph nodes from 6 patients without malignancy were tested ( 3 patients with pulmonary fibrosis, 2 patients with granulomatous disease, and 1 patient with blastomy-
TABLE 2. Detection of CEA mRNA by conventional versus quantitative RT-PCR in patients with stage I NSCLC

\begin{tabular}{lcc}
\hline & $\begin{array}{c}\text { Standard } \\
\text { CEA RT-PCR }\end{array}$ & $\begin{array}{c}\text { Quantitative } \\
\text { CEA RT-PCR }\end{array}$ \\
\hline Total patients tested & 53 & 53 \\
$\begin{array}{l}\text { Total negative nodes } \\
\text { according to hematoxylin } \\
\quad \text { and eosin stain }\end{array}$ & 232 & 232 \\
Positive lymph nodes & & \\
\hline
\end{tabular}

TABLE 3. RT-PCR restaging of stage I NSCLC disease

\begin{tabular}{lccc}
\hline & & \multicolumn{2}{c}{ Restaged cases } \\
\cline { 3 - 4 } $\begin{array}{l}\text { Stage according to hema- } \\
\text { toxylin and eosin staining }\end{array}$ & $\begin{array}{c}\text { Stage according } \\
\text { to RT-PCR }\end{array}$ & $\begin{array}{c}\text { Standard } \\
\text { RT-PCR }\end{array}$ & $\begin{array}{c}\text { Quantitative } \\
\text { RT-PCR }\end{array}$ \\
\hline IA & IIA & 3 & 5 \\
IA & IIIA & 8 & 10 \\
IB & IIIB & 2 & 1 \\
IB & IIIA & 10 & 14 \\
\hline
\end{tabular}

cosis). CEA mRNA was not detected in any of the control lymph nodes analyzed. A representative gel from a patient with pulmonary fibrosis is presented in Figure 2. Next 53 primary tumor and 232 lymph node specimens from 53 patients with stage I NSCLC were tested for CEA mRNA. Figure 3, A, shows a representative gel from a patient with T2 N0 disease with 2 of 4 lymph node stations expressing CEA mRNA according to RT-PCR. $\beta$-Actin was routinely amplified by RT-PCR in all samples in this study; this was indicative of total RNA integrity (data not shown). For internal assay validation a hematoxylin and eosin-positive lymph node station (11L) from a patient with T2 N1 disease was tested and found positive by RT-PCR (Figure 3, B). Of the 53 primary tumors analyzed, $39(73.6 \%)$ were CEA positive. Of the 232 lymph node specimens, 38 (16.4\%) were 


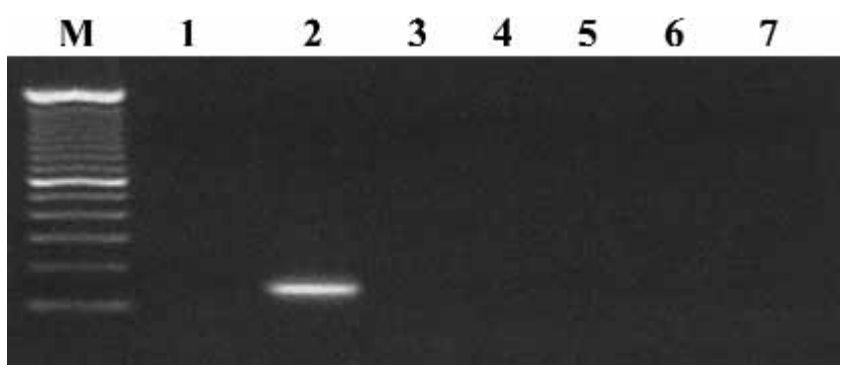

Figure 2. Standard RT-PCR for CEA mRNA in lymph node stations of patients without evidence of malignancy. RT-PCR reactions were analyzed by ethidium bromide-stained $2 \%$ agarose gel electrophoresis. Expected length of amplified PCR product representing CEA mRNA was 131 bp. Lane $M$, 100-bp molecular weight marker; lane 1, negative control; lane 2, HTB-174 lung adenocarcinoma positive control; lane 3 , lung mass (pulmonary fibrosis); lane 4, lymph node station 4R; lane 5, lymph node station 7; lane 6, lymph node station 10; lane 7, lymph node station 11.

CEA positive (Table 2). These 38 CEA mRNA-positive lymph nodes were distributed among 23 (43.4\%) of the 53 patients with stage I NSCLC as follows: 1 positive lymph node in 13 patients, 2 positive lymph nodes in 7 patients, 3 positive lymph nodes in 1 patient, 4 positive lymph nodes in 1 patient, and 5 positive lymph nodes in 1 patient. The potential stage changes are shown in Table 3. All patients with CEA-positive lymph node specimens also had CEApositive primary tumor specimens.

\section{Quantitative CEA RT-PCR}

After establishment of a reliable assay with a standard PCR approach, we extended these experiments to estimate with quantitative RT-PCR the number of CEA-expressing cells in lymph nodes of patients with NSCLC. For assay development CEA expression was initially tested on several tumor cell lines, and the assay sensitivity was then determined. According to quantitative RT-PCR, both the HTB174 and MCF-7 tumor cell lines (both CEA positive) expressed CEA mRNA. CEA mRNA was not detectable in NIH/3T3 cells or K562 cells (both CEA negative). With the same tumor cell line dilution experiments as in the standard RT-PCR assay, we found the sensitivity of CEA mRNA detection to be $10^{3}$ HTB-174 lung carcinoma cells in $10^{7}$ background NIH/3T3 cells. Identical results were obtained with K562 cells as background cells (data not shown). Next, 8 lymph nodes from 2 patients without malignancy (1 patient with pulmonary fibrosis and 1 patient with blastomycosis) were tested by quantitative RT-PCR for CEA mRNA. No CEA mRNA was detected $\left(\mathrm{C}_{\mathrm{T}}>45\right)$.

We then performed quantitative RT-PCR analysis on primary tumors and lymph nodes from the same 53 patients with stage I NSCLC. Of the 53 primary tumors, 48 (90.5\%)

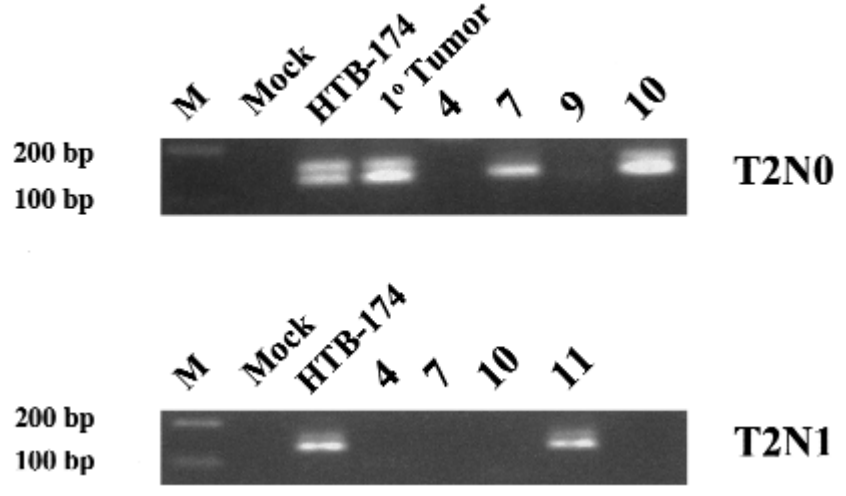

Figure 3. Standard RT-PCR for CEA mRNA in lymph node stations of patients with NSCLC. PCR reactions were analyzed by ethidium bromide-stained 2\% agarose gel electrophoresis. Expected length of amplified PCR product representing CEA mRNA was 131 bp. Lane $M$, 100-bp molecular weight marker; lane 1 (Mock), negative control; lane 2, HTB-174 lung adenocarcinoma positive control; other lanes, primary tumor and mediastinal lymph node stations as labeled. $A$, Patient with T2 N0 disease; B, patient with T2 N1 disease.

were positive for CEA mRNA. Of the 232 lymph node specimens analyzed, $59(25.4 \%)$ were positive for CEA mRNA (Table 2). Figure 4 shows a representative amplification plot of a patient's primary tumor and lymph nodes. These 59 CEA-positive lymph nodes were distributed among $30(56.6 \%)$ of the 53 patients as follows: 1 positive lymph node in 13 patients, 2 positive lymph nodes in 10 patients, 3 positive lymph nodes in 4 patients, 4 positive lymph nodes in 2 patients, and 5 positive lymph nodes in 1 patient. The potential stage changes are shown in Table 3. All patients with CEA-positive lymph node specimens also had CEA-positive primary tumor specimens.

For quantitative analysis of the number of metastatic tumor cells per lymph node, standard curves were created from serially diluted CEA-expressing tumor cell lines in a background of murine fibroblasts. Regression analysis of these standard curves was used to examine the linear relationship between starting quantity and $\mathrm{C}_{\mathrm{T}}$. This analysis routinely yielded excellent correlation $(r=0.99)$. When $\mathrm{C}_{\mathrm{T}}$ values of lymph nodes were compared with tumor cell line standard curves, estimated occult micrometastatic burden ranged from $1.0 \times 10^{3}$ to $3.2 \times 10^{5}$ micrometastatic cells per lymph node station. The median cell number was 7190 tumor cells per lymph node station.

Analysis of variance was used to examine the relationship between the estimated micrometastatic tumor cell burden determined by quantitative RT-PCR with primary tumor histologic type and $\mathrm{T}$ status. No statistical difference was observed between adenocarcinomas (median 7425 tumor cells), squamous cell carcinomas (median 11,165 tumor cells), and undifferentiated tumors (median 7190 tumor cells). 


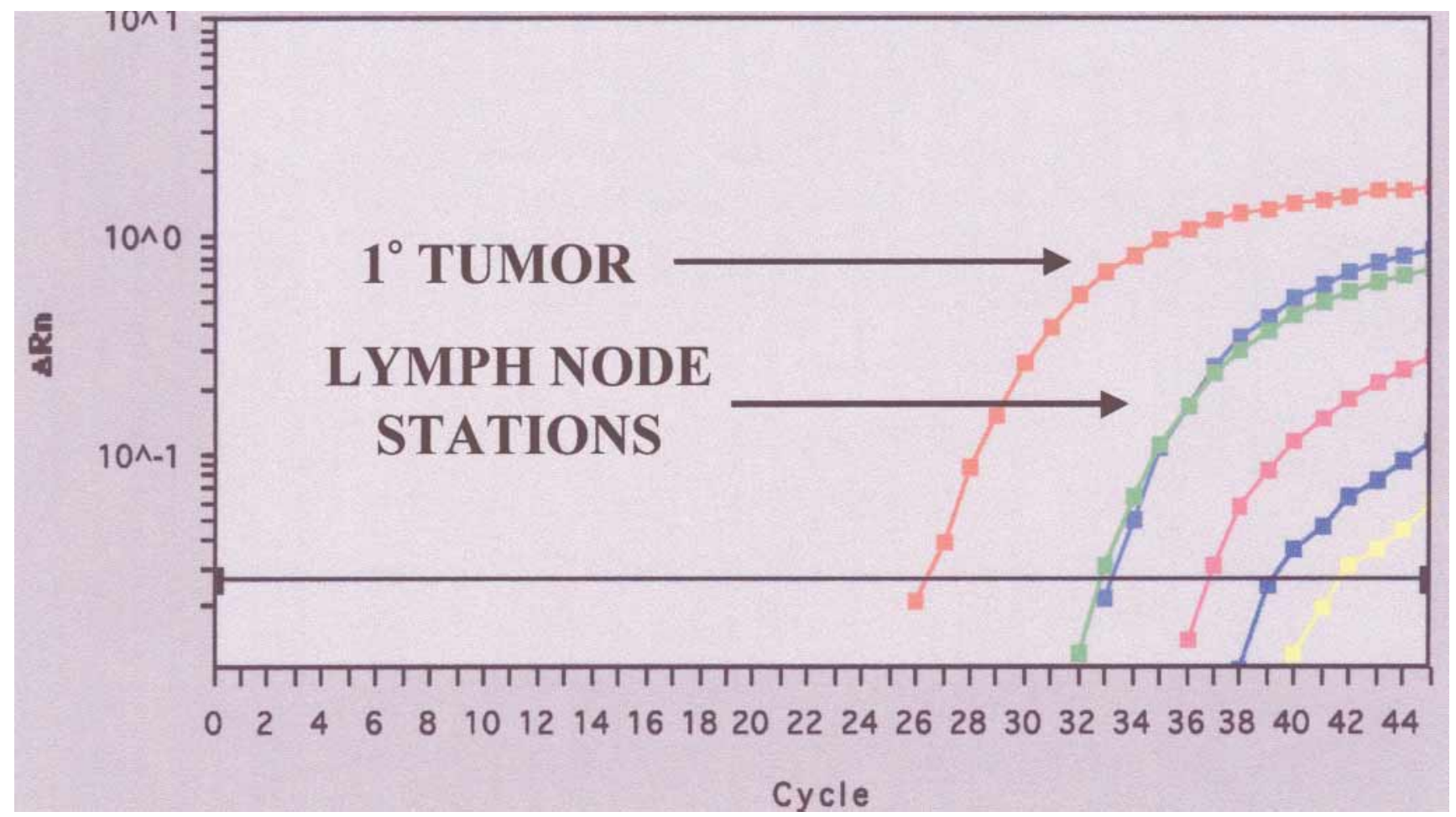

Figure 4. Representative quantitative RT-PCR amplification plot of patient with stage I NSCLC. Change in normalized reporter signal ( $\Delta R n, y$-axis) plotted versus cycle number (x-axis). Amplification curves for primary tumor and lymph node stations are shown. Amplification curves are as follows: orange, primary tumor; green, station 4R; blue, station 9; red, station 10; dark blue; station 11; yellow, station 7.

Of the 134 T1 N0 lymph node stations analyzed, 32 $(23.9 \%)$ were positive for CEA mRNA. This was not significantly different from the $26(27.6 \%)$ of 98 CEA-positive T2 N0 lymph node stations. Further, no difference was observed between T1 (median 7730 tumor cells) and T2 (median 6580 tumor cells) tumors.

\section{Discussion}

This represents the first report demonstrating the utility of CEA as a marker for micrometastatic disease in lymph nodes of patients with NSCLC. CEA is a member of a heterogeneous group of oncofetal membrane glycoprotein antigens that are frequently overexpressed in epithelialderived tumors. Because of this overexpression, CEA mRNA detection in the lymph nodes, serum, and bone marrow of patients may be of value as a marker for the presence of occult micrometastases. Recently CEA mRNA detection by RT-PCR was shown to predict a significantly worse prognosis in patients with stage II colon cancer, supporting its potential value as a marker for occult micrometastases. ${ }^{16}$

Few studies have evaluated CEA mRNA expression by RT-PCR in NSCLC. ${ }^{11,12,17,18}$ Castaldo and coworkers ${ }^{11}$ evaluated RT-PCR for CEA mRNA detection in 24 patients with advanced NSCLC. CEA mRNA was detected in the peripheral blood of 8 of 10 patients with distant metastases. Of 14 patients without distant metastases, 4 had CEA-positive samples; 2 of those 4 had distant metastases develop within 6 months. Kurusu and colleagues ${ }^{12}$ tested peripheral blood samples of NSCLC patients before operation and then 2 to 3 weeks after tumor resection. Of the 103 patients in their analysis, 62 had CEA mRNA detected before the operation; of these, 27 still had CEA mRNA detected after the operation, which suggests persistent systemic disease. Neither study provided data on tumor recurrence.

The technique of quantitative RT-PCR uses a sequencespecific oligonucleotide probe with a covalently attached fluorescent reporter and quencher dye. When the probe is intact, the quenching dye absorbs the fluorescent energy of the reporter dye. If the target molecule of interest (in this case CEA mRNA) is present, the specific oligonucleotide probe will anneal to it. During the PCR extension phase, the probe is cleaved by the $5^{\prime}$ to $3^{\prime}$ exonuclease activity of Taq DNA polymerase, thus increasing the reporter dye's emission. Curves plotting relative fluorescence change against PCR cycle number are constructed, and the point of fluorescence increase above background is calculated. From 
this calculation the $\mathrm{C}_{T}$ is determined. Because the $\mathrm{C}_{T}$ value decreases linearly with increasing target molecule quantity in the input sample, it provides quantitative measurement.

Other reports have attempted to quantitate occult micrometastatic burden by analyzing lymph nodes from patients with colorectal and gastric cancers to detect CEA mRNA with a variant of real-time RT-PCR that employs nonspecific DNA-binding fluorescent dyes. ${ }^{19,20}$ A potential disadvantage of this approach is its inherent lack of specificity. Because of this, PCR-product discrimination is necessary through the additional step of double-stranded DNA-based fluorescence melting curve analysis. The technique in our study used a CEA sequence-specific probe for quantitative RT-PCR.

For normalization of CEA mRNA values in each specimen, we also quantitated $\beta$-actin mRNA levels in RT-PCR (standard and quantitative RT-PCR) experiments. $\beta$-Actin levels varied among samples but did not differ significantly overall. Because our results were not significantly altered by CEA to $\beta$-actin normalization, the rationale for reporting normalized data in this setting may be limited. ${ }^{20}$ Also, the total number of cancer cells in a given lymph node station, rather than the cancer to noncancer cell ratio, may be the critical parameter predicting recurrence. For these reasons we have reported unnormalized CEA mRNA data as an indicator of occult micrometastatic burden. This has been internally validated through an analysis of patients with stage II and stage III disease, who uniformly had higher numbers of metastatic cells in their hematoxylin and eosin-positive lymph nodes.

The results of our quantitative RT-PCR assay suggest that the number of metastatic tumor cells in a lymph node can be estimated by measurement of CEA mRNA abundance. How the quantity of CEA mRNA correlates with the number of tumor cells is imprecisely defined. Others have previously shown CEA mRNA and protein expressions to be linearly coupled. ${ }^{21}$ Thus if the same cell line is used consistently, a standard curve derived from CEA mRNA levels should allow reproducible estimates of tumor cell number.

In our analysis quantitative RT-PCR appeared to be more sensitive than standard PCR for detecting CEA mRNA. Quantitative RT-PCR found 20 additional CEA-positive lymph nodes (all negative by standard PCR), potentially upstaging 7 additional cases. This finding is consistent with the 10-fold increased sensitivity of the quantitative RT-PCR technique relative to standard RT-PCR in our cell line experiments. The finding of 20 additional CEA-positive lymph node stations by quantitative RT-PCR is entirely related to the increased sensitivity of the assay, because the number of estimated micrometastatic cells in quantitative RT-PCR-positive and standard RT-PCR-negative lymph node stations was less than 10,000 tumor cells per lymph node station. Quantitative RT-PCR may therefore offer greater sensitivity than standard RT-PCR for detecting occult micrometastases.
Although quantitative RT-PCR does appear to have greater sensitivity than standard RT-PCR for detection of occult micrometastases, the results are remarkably similar and consistent. Standard RT-PCR and quantitative RT-PCR demonstrate similar rates of lymph node occult micrometastatic detection (16.4\% and $25 \%$, respectively) and potential upstaging (43.4\% and 56.6\%, respectively). Quantitative RT-PCR trended toward discriminating more patients with micrometastatic disease, and any significant differences in sensitivity between the two techniques will probably be identified by the completion of CALGB 9761. In additional to the advantage of quantitative analysis, quantitative RT-PCR also decreases the amount of experimental time (from 8 hours with standard RT-PCR to 3 hours with quantitative RT-PCR) and affords a 2-fold increase in samples analyzed per experiment.

The similarity in numbers of tumor cells per lymph node station determined by quantitative RT-PCR in patients with T1 N0 versus T2 N0 disease is surprising in light of the known survival difference between these groups of patients. Further, the rates of CEA-positive lymph nodes were similar in patients with $\mathrm{T} 1 \mathrm{~N} 0$ and $\mathrm{T} 2 \mathrm{~N} 0$ disease $(23.9 \%$ and $27.6 \%$, respectively). It remains unclear whether survival differences between patients with $\mathrm{T} 1$ and $\mathrm{T} 2$ lesions is accounted for solely by the presence of undetected metastatic nodal disease. For example, a variety of molecular abnormalities have been associated with increased tumor size that may account for differences in patient outcome independent of micrometastatic disease..$^{22,23}$

In summary, quantitative RT-PCR can estimate the number of micrometastatic cells per lymph node, potentially allowing greater precision than either standard RT-PCR or immunohistochemical analysis in assessing tumor recurrence risk. The potential stage change rates are similar to the known 5-year survival rates for surgically resected stage I disease. The comparative prognostic values of immunohistochemical analysis, standard RT-PCR, and quantitative RT-PCR should be clarified by the tumor recurrence rates and survival data provided by the results of CALGB 9761.

We are indebted to Dr Catherine Verfaillie for the use of the PE Biosystems Prism 7700 instrument. We also thank Ms Debra Herzan for timely and accurate assistance with clinical and pathologic data reported in this study. We are grateful for the expert editorial remarks provided by Dr Mary Knatterud.

\section{References}

1. Landis SH, Murray T, Bolden S, Wingo PA. Cancer statistics, 1999. CA Cancer J Clin. 1999;49:8-31, 1.

2. Mountain CF. Revisions in the International System for Staging Lung Cancer. Chest. 1997;111:1710-7.

3. Passlick B, Izbicki JR, Kubuschok B, Nathrath W, Thetter O, Pichlmeier $U$, et al. Immunohistochemical assessment of individual tumor cells in lymph nodes of patients with non-small-cell lung cancer. J Clin Oncol. 1994;12:1827-32. 
4. Pantel K, Braun S, Schlimok G, Riethmuller G. Micrometastatic tumour cells in bone marrow in colorectal cancer [letter]. Lancet. 1993;341:501.

5. Salerno CT, Frizelle S, Niehans GA, Ho SB, Jakkula M, Kratzke RA, et al. Detection of occult micrometastases in non-small cell lung carcinoma by reverse transcriptase-polymerase chain reaction. Chest. 1998;113:1526-32.

6. Bostick PJ, Chatterjee S, Chi DD, Huynh KT, Giuliano AE, Cote R, et al. Limitations of specific reverse-transcriptase polymerase chain reaction markers in the detection of metastases in the lymph nodes and blood of breast cancer patients. J Clin Oncol. 1998;16:2632-40.

7. Brugger W, Buhring HJ, Grunebach F, Vogel W, Kaul S, Muller R, et al. Expression of MUC-1 epitopes on normal bone marrow: implications for the detection of micrometastatic tumor cells. J Clin Oncol. 1999:17:1535-44.

8. Dent GA, Civalier CJ, Brecher ME, Bentley SA. MUC1 expression in hematopoietic tissues. Am J Clin Pathol. 1999;111:741-7.

9. Mori M, Mimori K, Inoue H, Barnard GF, Tsuji K, Nanbara S, et al. Detection of cancer micrometastases in lymph nodes by reverse transcriptase-polymerase chain reaction. Cancer Res. 1995;55:3417-20.

10. Gerhard M, Juhl H, Kalthoff H, Schreiber HW, Wagener C, Neumaier M. Specific detection of carcinoembryonic antigen-expressing tumor cells in bone marrow aspirates by polymerase chain reaction. $J$ Clin Oncol. 1994:12:725-9.

11. Castaldo G, Tomaiuolo R, Sanduzzi A, Bocchino ML, Ponticiello A, Barra E, et al. Lung cancer metastatic cells detected in blood by reverse transcriptase-polymerase chain reaction and dot-blot analysis. J Clin Oncol. 1997;15:3388-93.

12. Kurusu Y, Yamashita J, Ogawa M. Detection of circulating tumor cells by reverse transcriptase-polymerase chain reaction in patients with resectable non-small-cell lung cancer. Surgery. 1999;126:820-6.

13. Luke WP, Pearson FG, Todd TR, Patterson GA, Cooper JD. Prospective evaluation of mediastinoscopy for assessment of carcinoma of the lung. J Thorac Cardiovasc Surg. 1986;91:53-6.

14. Gibson UE, Heid CA, Williams PM. A novel method for real time quantitative RT-PCR. Genome Res. 1996;6:995-1001.

15. Heid CA, Stevens J, Livak KJ, Williams PM. Real time quantitative PCR. Genome Res. 1996;6:986-94.

16. Liefers GJ, Cleton-Jansen AM, van de Velde CJ, Hermans J, van Krieken $\mathrm{JH}$, Cornelisse CJ, et al. Micrometastases and survival in stage II colorectal cancer. $N$ Engl J Med. 1998;339:223-8.

17. Yamashita JI, Kurusu Y, Fujino N, Saisyoji T, Ogawa M. Detection of circulating tumor cells in patients with non-small cell lung cancer undergoing lobectomy by video-assisted thoracic surgery: a potential hazard for intraoperative hematogenous tumor cell dissemination. $J$ Thorac Cardiovasc Surg. 2000;119:899-905.

18. Fujita J, Ueda Y, Bandoh S, Namihira H, Ishii T, Takahara J. A case of leptomeningeal metastasis from lung adenocarcinoma diagnosed by reverse transcriptase-polymerase chain reaction for carcinoembryonic antigen. Lung Cancer. 1998;22:153-6.

19. Miyake Y, Fujiwara Y, Ohue M, Yamamoto H, Sugita Y, Tomita N, et al. Quantification of micrometastases in lymph nodes of colorectal cancer using real-time fluorescence polymerase chain reaction. Int $J$ Oncol. 2000;16:289-93.

20. Nakanishi H, Kodera Y, Yamamura Y, Ito S, Kato T, Ezaki T, et al Rapid quantitative detection of carcinoembryonic antigen-expressing free tumor cells in the peritoneal cavity of gastric-cancer patients with real-time RT-PCR on the lightcycler. Int J Cancer. 2000;89:411-7.

21. Kim J, Kaye FJ, Henslee JG, Shively JE, Park JG, Lai SL, et al. Expression of carcinoembryonic antigen and related genes in lung and gastrointestinal cancers. Int J Cancer. 1992;52:718-25.

22. Kratzke RA, Greatens TM, Rubins JB, Maddaus MA, Niewoehner $\mathrm{DE}$, Niehans GA, et al. Rb and p16INK4a expression in resected nonsmall cell lung tumors. Cancer Res. 1996;56:3415-20.

23. Greatens TM, Niehans GA, Rubins JB, Jessurun J, Kratzke RA, Maddaus MA, et al. Do molecular markers predict survival in nonsmall-cell lung cancer? Am J Respir Crit Care Med. 1998;157:1093-7.

\section{Discussion}

Dr James Luketich (Pittsburgh, Pa). This exciting work is timely in light of the interest in neoadjuvant therapy for early- stage lung cancer. We have done some similar work with esophageal cancer.

I have two questions. First, did background gene expression of CEA seem to be present in your patients that did not have lung cancer (benign negative control)? We have seen that as a possible complicating problem for the specificity of this assay in determining what really represents background gene expression versus what represents a micrometastasis. Second, did you find any correlation with a worsening prognosis in terms of clinical outcomes and cancer recurrences?

Dr D'Cunha. To address the first question, in our 6 patients with benign conditions we did not see any background expression under the described assay conditions, although it was a relatively small number of patients. Perhaps when we expand our negative control population, which we will do as part of our ongoing work, we will see some background expression. I think that the advantage of quantitative RT-PCR is that it potentially allows you to at least exclude the population that would express it at baseline.

To address the second question, this is part of a prospective, multi-institutional clinical trial, and we have not looked at the survival data and compared our results with that yet. We will be doing that as we get more patients, and then we should be able to correlate those results.

Dr Raphael Bueno (Boston, Mass). I think that molecular markers are going to help us significantly in classification and staging. I do have a cautionary note. Until you can show that the CEA correlates with the actual presence of cancer cells, it is incorrect to use the term micrometastatic disease, which at least in my mind implies that there are cancer cells there. The CEA levels could be representing background noise, or the antigen could be made by cells in the process of carcinogenesis. I suggest that we add molecular markers to our current staging scheme, as we do in breast cancer with progesterone and estrogen receptors, to direct therapy rather than just upstaging the cancer as you suggest.

Dr David Harpole, Jr (Durham, NC). For the audience, these data are part of a large multi-institutional Cancer and Leukemia Group B Thoracic Surgery Subcommittee study, which is analyzing these data in more than 500 patients. We anxiously await the complete results from Dr Maddaus' laboratory.

I have two questions. First, the abstract and presentation omitted the percentage of the primary tumors that expressed CEA. It would have to be present in most to accurately reflect micrometastatic disease in lymph nodes. Was this the case? Second, have you attempted these techniques on formalin-fixed, paraffin-bedded tumors? I know that it is difficult, but it can be done. We have done it in our laboratory, and it clearly makes these techniques much more applicable at most North American hospitals.

Dr D'Cunha. With respect to the paraffin-embedded tissue, we have not tried that, but I know that it is being done and potentially would be an area for our future investigation. With respect to the percentage of positive results in the primary tumors, that is an excellent question. In the standard RT-PCR the primary tumors were $75 \%$ positive for CEA, whereas in quantitative RT-PCR the rate was about $90 \%$. We attribute that difference to the 10 -fold increased sensitivity that the quantitative RT-PCR assay affords. 